\title{
Ty3 integrates within the region of RNA polymerase III transcription initiation
}

\author{
Douglas L. Chalker and Suzanne B. Sandmeyer ${ }^{1}$ \\ Department of Microbiology and Molecular Genetics, University of California, Irvine, Irvine, California 92717 USA
}

\begin{abstract}
Over 190 independent insertions into target plasmids of the retrovirus-like element Ty3 were recovered and mapped. Ty3 was shown to insert upstream of tRNA, 5S, and U6 genes, all of which are transcribed by RNA polymerase III. Integration sites were within 1-4 nucleotides of the position of transcription initiation, even for one mutant gene where the polymerase III initiation site was shifted to a completely new context.

Mutagenesis of a SUP2 tRNA gene target showed that integration required functional promoter elements but that it did not correlate in a simple way with target transcription. This is the first report directly linking a discrete genomic function with preferential insertion of a retrotransposon.
\end{abstract}

[Key Words: Integration; RNA polymerase III; retrotransposon; retrovirus; Ty3; yeast]

Received September 27, 1991; revised version accepted November 19, 1991.

Although many of the molecular details of the integration of retroviruses and retrotransposons have been defined, little is known about factors that influence selection of the insertion site in vivo. Data from several laboratories indicate that target selection is not a random process (for review, see Sandmeyer et al. 1990). Previous studies have demonstrated that integration may occur preferentially into accessible regions of chromatin as defined by DNase I hypersensitivity (Robinson and Gagnon 1986; Vijaya et al. 1986; Rohdewohld et al. 1987) and into DNA being actively transcribed (Scherdin et al. 1990). Shih et al. (1988) identified a small number of sites targeted by Rous sarcoma virus at a frequency $\sim 1,000,000$ times that expected for random insertion. Selected insertions of the Saccharomyces retrotransposon Ty1, which inactivated target genes, occurred predominantly within the $5^{\prime}$ portion of the LYS2, URA3, and CAN1 genes (Eibel and Philippsen 1984; Simchen et al. 1984; Natsoulis et al. 1989; Wilke et al. 1989). However, in the case of insertions inactivating the CAN1 gene, the insertion-site bias was strain dependent (Wilke et al. 1989).

The development of in vitro systems has facilitated characterization of the mechanism of integration of retroviruses and retrotransposons. Although nucleocapsids cofractionate with integration activity (Brown et al. 1987; Eichinger and Boeke 1988; Bowerman et al. 1989; Fujiwara and Craigie 1989), the viral integrase protein (IN) has been shown to be sufficient for cutting and joining naked DNA in vitro (Katzman et al. 1989; Craigie et al. 1990; Katz et al. 1990). In vitro integration into naked DNA targets appears to be relatively random (Brown et

${ }^{1}$ Corresponding author. al. 1987; Eichinger and Boeke 1988). In vitro integration of Moloney murine leukemia virus (MoMLV) DNA mediated by viral cores into a chromatin substrate showed no concentration of insertions in the nucleosome-free region but did show a pattern of insertions at 10-bp intervals consistent with a role for chromatin proteins in insertion site selection (Pryciak et al. 1991).

The retrotransposon Ty3 is one of four known retroelements in Saccharomyces (for review, see Boeke and Sandmeyer 1991). It is fundamentally similar to retroviruses in encoded protein sequence and gene organization (Hansen et al. 1988). This 5.4-kbp element consists of an internal domain flanked by long terminal repeats (LTRs) of 340 bp called $\sigma$ (Clark et al. 1988). The genomic RNA contains two overlapping open reading frames (ORFs), GAG3 and POL3, referred to previously as TYA3 and TYB3, respectively. These reading frames encode proteins that are homologous to retroviral gag and pol gene products. GAG3- and POL3-encoded proteins have been shown to assemble with the RNA to form viruslike particles (VLPs) analogous to retroviral cores (Hansen and Sandmeyer 1990; Hansen et al. 1991). Expression of Ty3 RNA under the transcriptional control of the GAL1-10 upstream activating sequence (UAS) (Johnston and Davis 1984) results in detectable transposition (Hansen et al. 1988). Newly integrated elements are flanked by characteristic 5-bp direct repeats of host sequence. Transfer RNA genes were shown to be the primary genomic targets of de novo transposition with Ty3 integrating within 16 or 17 nucleotides from the $5^{\prime}$ ends of coding regions for mature tRNAs (Chalker and Sandmeyer 1990). No insertion site consensus sequence could be deduced, and Ty3 does not have tRNA gene-sequence similarity.

Although different genomic tRNA gene families are 
quite distinct in sequence, they do contain conserved patterns corresponding to tRNA secondary structure and RNA polymerase III promoter motifs. Two promoter elements, box $A$ and box $B$ (for review, see Geiduschek and Tocchini-Valentini 1988), direct assembly of the polymerase III transcription complex on the gene. The box $B$ element is the primary recognition element for transcription factor C (TFIIIC) (Camier et al. 1985; Baker et al. 1986), whereas box $A$ apparently ensures proper positioning of this factor for transcription initiation (Ciliberto et al. 1983). TFIIIC mediates binding of TFIIIB (Lassar et al. 1983; Segall 1986) upstream of the initiation site (Kassavetis et al. 1989). Polymerase III initiates transcription on the factor-bound template.

The following study was undertaken to identify features of tRNA genes that make them targets for Ty3 integration. An assay was developed to recover insertions of a marked Ty3 element into a plasmid at positions that did not depend on a phenotypic effect stemming from the position of the insertion. This assay allowed investigation, for the first time, of the relative contributions of primary sequence and transcriptional activity to in vivo targeting of a retrotransposon. Integration occurred exclusively near the site of transcription initiation of the target tRNA gene and was dependent upon intact promoter elements. In addition, we show here that other genes transcribed by polymerase III, $5 \mathrm{~S}$ and $\mathrm{U} 6$ genes, can also serve as targets of Ty3 integration.

\section{Results}

Recovery of Ty3 insertions into target plasmids

High-level expression of Ty3 RNA results in Ty3 transposition (Hansen et al. 1988) into sites upstream of genomic tRNA genes (Chalker and Sandmeyer 1990). To determine what features of the tRNA gene mediate targeting, an assay was developed to recover transposed elements in target plasmids independent of the site of integration. In this assay, summarized in Figure 1, the donor Ty3 element, Ty3-N, was tagged with the bacterial neor ${ }^{r}$ gene, which confers G418 resistance in yeast. Transposition experiments were performed using yeast strain yDLC221. This strain contains an integrated, galactose-inducible, Ty3 helper element that is required to provide the essential proteins in trans because the Ty3coding region is disrupted by the neor gene in Ty3-N. The Ty3-N element was placed on a low-copy, URA3 plasmid, to produce donor plasmid pDLC348.

The SUP2 tRNA ${ }^{\text {Tyr }}$ gene was cloned onto a high-copy, HIS3-marked shuttle vector to provide multiple plasmid targets per cell. This tRNA gene was chosen because
Figure 1. Transposition assay. Yeast strain yDLC221 containing a galactose-inducible, Ty3-1 element was transformed with both a low-copy URA3 donor plasmid (pDLC348) containing a neormarked Ty3 element (Ty3-N) and a high-copy HIS3 $a m p^{r}$ target plasmid (pDLC300 in this illustration, containing the wild-type SUP2 tRNA ${ }^{\text {Tyx }}$ gene). The procedure for isolation of the targeted plasmids is summarized at bottom.

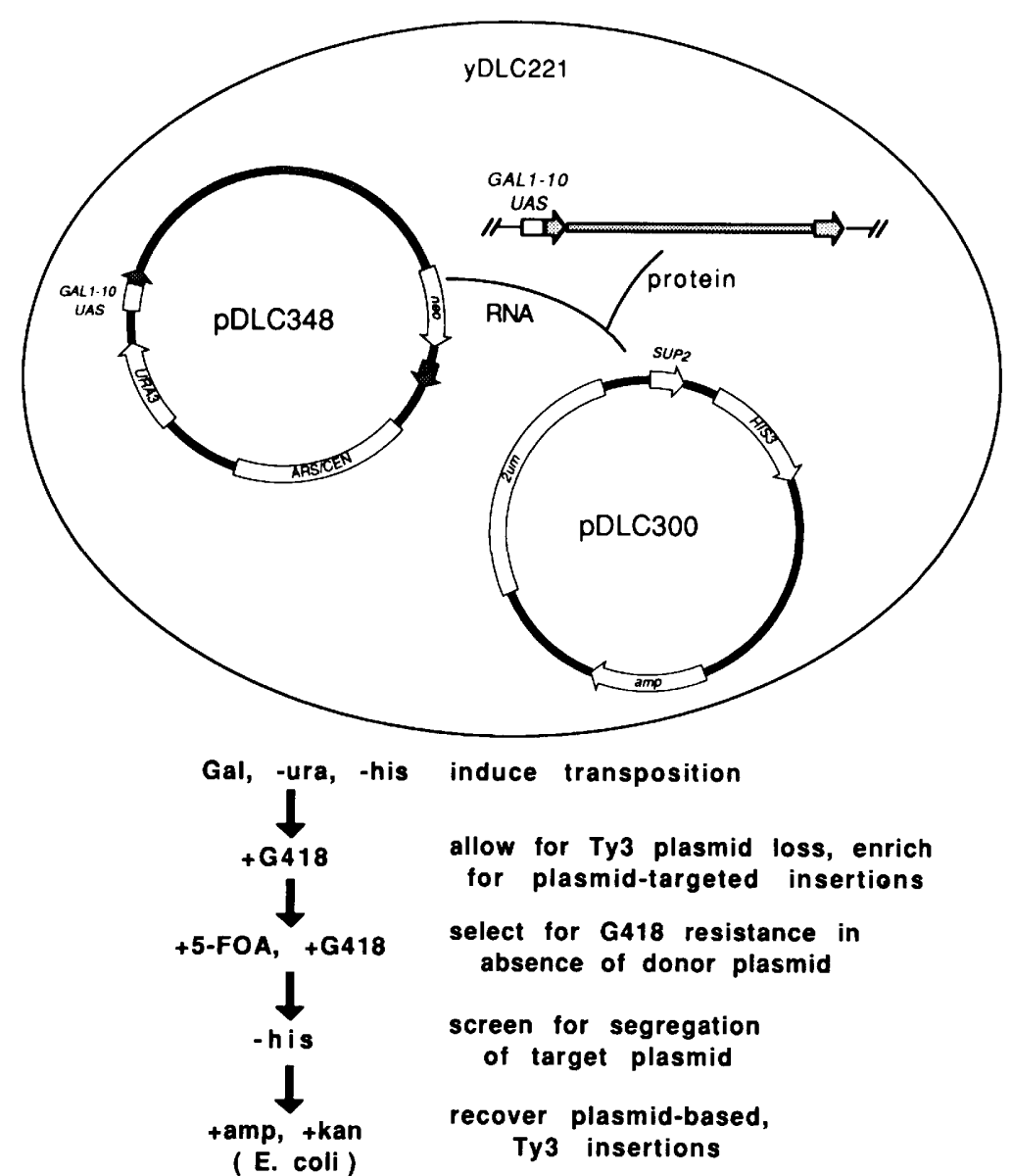


yeast strains had been identified previously that contained a $\sigma$ element at the SUP2 locus (Sandmeyer and Olson 1982|, suggesting that it is a target for Ty3 transposition. The SUP2 gene is a member of a family of eight tRNA $^{\text {Tyr }}$ genes of identical structural sequence, and de novo Ty3 transposition upstream of another member of the tRNA ${ }^{\text {Tyr }}$ gene family had also been detected /Chalker and Sandmeyer 1990). In addition, transcriptional properties of the tRNA ${ }^{\text {Tyr }}$ gene family have been studied extensively (Kurjan and Hall 1982; Allison et al. 1983; Baker et al. 1986; Kassavetis et al. 1989; Kassavetis et al. 1990).

The target plasmid carrying the SUP2 gene, pDLC300, was cotransformed with donor plasmid pDLC348, containing the Ty3-N element into yeast strain yDLC221. Transposition was induced by plating these transformants on medium containing galactose. Individual, galactose-induced colonies were transferred to rich medium (YPD) containing G418. This level of G418 (700 $\mu \mathrm{g} / \mathrm{ml}$ ) enriched for cells in which Ty3-N insertions had occurred into the high-copy target plasmid. G418-resistant cells that had lost the URA3-containing donor plasmid were then selected on medium containing 5-fluoroorotic acid (5-FOA). 5-FOA is toxic to cells containing an active $U R A 3$ gene. The G418-resistant colonies that retained the HIS3-marked target plasmid in a high proportion of cells were identified on synthetic medium lacking histidine. DNA was isolated from these cells, and plasmids containing Ty3-N insertions were recovered by transformation of Escherichia coli to kanamycin and ampicillin resistance. Plasmid DNA was isolated and analyzed from a single $E$. coli transformant per galactoseinduced colony to ensure that the Ty3- $\mathrm{N}$ insertions were independent. Transposed elements were not observed in the absence of galactose induction. In the experiments described below, 198 independent Ty3-N integrations into target plasmids were recovered from 538 individual, galactose-induced colonies carried through the selection scheme. That is, after induction, approximately one in three 5-FOA-, G418-resistant colonies that had retained the target plasmid at a high frequency had Ty3-N insertions in that plasmid. The sites of Ty3 insertion were determined, at a resolution of $\sim 50 \mathrm{bp}$, by restriction enzyme digestion in all cases and were further defined by DNA sequence analysis in a number of these.

A total of 144 Ty3-N insertions have been mapped by restriction digestion to positions upstream of the SUP2 gene carried alone or together with a second test gene on the target plasmid. The orientation of integrated Ty3 elements appeared nearly random as 76 insertions were oriented so that transcription of the tRNA and the Ty3 were divergent, and 68 were observed in the opposite orientation. The positions of 14 insertions into plasmids bearing the SUP2 gene were determined by DNA sequence analysis and were shown to be situated so that the Ty3 sequence started upstream within 15-18 nucleotides of the beginning of the coding region for the mature tRNA. Taking into account the 5-bp duplication generated upon integration, the gene-proximal nick at the target site would have occurred within 3 nucleotides of the transcription initiation site and within 13 nucleotides of the coding region (discussed below). Despite the presence on the target plasmid of $>4 \mathrm{kbp}$ of DNA not essential for plasmid maintenance in yeast or E. coli, Ty3 integrations were recovered exclusively in the upstream flank of the tRNA gene. We cannot exclude the possibility that insertion could have occurred into positions on the plasmid that disrupted required function of some component essential for plasmid maintenance or that it occurred into other positions infrequently and therefore was not observed. Nevertheless, these results showed that a tRNA gene on a plasmid is a highly preferred target of Ty 3 transposition and that when this member of the tRNA $^{\text {Tyr }}$ gene family was used as a target, the positions of integration varied within a small number of bases close to the initiation site.

\section{The ability to bind polymerase III transcription factors is an essential feature of Ty3 integration targets}

The preceding results, together with those from a study of genomic integration (Chalker and Sandmeyer 1990), suggested that tRNA gene targets were not distinguished by a particular sequence at the insertion site but, rather, by some common feature(s) of tRNA genes, such as promoter elements or transcription factors. The plasmid target assay was therefore used to investigate whether a functional promoter was required for targeting. To inactivate the tRNA gene transcriptionally, a single-basepair mutation was introduced into the box $B$ sequence, which is well separated from the insertion site. To monitor expression of this and other mutant genes, a wildtype gene was first modified by insertion of $6 \mathrm{bp}$ into the $14-b p$ intron, creating a $B s t$ EII site $(\sup 2+b)$. This insertion allowed specific detection of RNA synthesized from the marked gene by reverse primer extension with an oligonucleotide complementary to $\sup 2+b$ pre-tRNA (Kinsey and Sandmeyer 1991). The tRNA or pre-tRNA produced from unmarked genomic or plasmid-based tRNA $^{\text {Tyr }}$ genes was not significantly detectable under our extension conditions. A conserved $\mathrm{C}$ at nucleotide position 56 of the tRNA gene [defined relative to tRNAPhe (Sprinzl et al. 1989), but actually at nucleotide 83 of the SUP2 tRNA gene (see Fig. 2A)] was changed to $\mathrm{G}$ in the SUP2 gene (sup2G56) and the sup $2+b$ gene $(\sup 2 \mathrm{G} 56+b)$. The $\mathrm{C} 56 \rightarrow \mathrm{G}$ mutation in box $B$ was shown previously to eliminate suppression by the gene for a tRNA ${ }^{\mathrm{Tyr}}$ ochre suppressor (Kurjan and Hall 1982). In vitro this mutation was shown to decrease transcription of the SUP4 tRNA $^{\mathrm{Tyr}}$ gene to $5 \%$ of wild type (Allison et al. 1983) by severely reducing the ability of box $B$ to bind TFIIIC (Baker et al. 1986). Extension of primers complementary to sup $2+b$ using template RNA extracted from control cells transformed with a plasmid carrying the sup $2+b$ gene showed products representing both pre-tRNA and end-processed pre-tRNA, but RNA extracted from cells transformed with the plasmid containing the sup $2 G 56+b$ gene showed no evidence of pretRNA (Fig. 2B). 
A

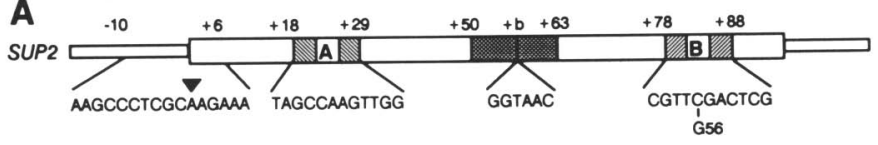

C

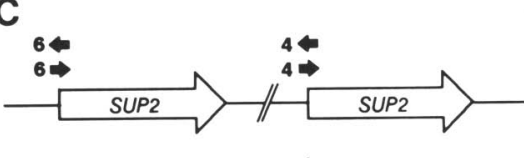

Relative target activity SUP2 : test gene

12: 8
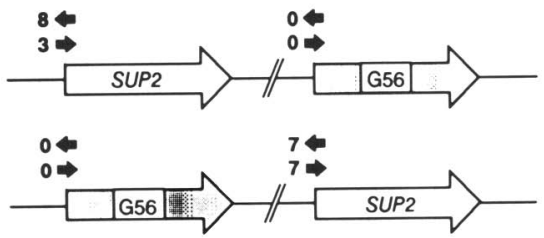

25:0

Figure 2. Assessment of Ty3 integration into a wild-type and a transcriptionally inactive tRNA gene. $(A)$ A schematic representation of the SUP2 $\mathrm{tRNA}^{\mathrm{Tyr}}$ gene is shown at top. The wide, open box indicates the transcribed portion of the gene; the narrow, open boxes represent flanking sequence; hatched boxes are internal promoter elements box $A$ and box $B$; the crosshatched box depicts the 14-nucleotide intron within the gene; $+b$ indicates the position of a 6 -nucleotide insertion within the intron, which created a BstEII site, used to mark the pre-tRNA for primer extension analysis. Pertinent sequences and their corresponding positions are given below and above the gene, respectively. The C56 $\rightarrow \mathrm{G}$ change [by conventional tRNA numbering (Sprinzl et al. 1989)], which greatly reduces TFIIIC binding, is shown. (Solid arrowhead) The major transcription initiation site as determined by reverse primer extension. $(B)$ Total RNA isolated from cells transformed with target plasmids bearing the wild-type SUP2 (S), the BstEII-marked $\sup 2+b(\mathrm{~S}+\mathrm{b})$, or the $\sup 2+b$ containing the $\mathrm{G} 56$ boxB mutation $(\mathrm{G}+\mathrm{b})$ was used for primer extension analysis using a ${ }^{32} \mathrm{P}$-labeled oligonucleotide complementary to the sup $2+b$ pre-tRNA. The DNA sequence ladder was generated using sup $2+b$ DNA and the same labeled primer. The open box depicts the coding region of the 5 '-end processed tRNA; the hatched box indicates the boxA promoter element. The nucleotide sequence upstream of the region encoding the mature tRNA is shown. (Solid arrowhead) The major transcription initiation site. $(C)$ Summary of relative usage of wild-type and mutant tRNA gene targets. Large open and shaded arrows represent wild-type and mutant SUP2 genes (G56), respectively; small solid arrows depict Ty3 insertions and point in the direction of Ty3 transcription. The number of observed insertions upstream of each gene is given beside each arrow, and the ratio of SUP2 to test gene insertions is totaled at right.

The transcriptionally inactive sup2G56 gene was tested for its activity as a target for Ty 3 transposition. To directly compare the frequencies at which the mutant and wild-type targets were used, the target plasmid was modified to contain two tandem tRNA genes in the same orientation with respect to transcription. Two wild-type SUP 2 genes carried in tandem (separated by $\sim 1 \mathrm{kbp}$ ) each acted as integration targets (Fig. 2C). In this case, of 20 independent insertions recovered, 12 were into the upstream gene and 8 were into the downstream gene. The sup2G56 gene was placed both upstream and downstream of a $S U P 2$ gene to control for potential positional effects. Of the 25 Ty3 insertions analyzed, all occurred upstream of the wild-type gene (Fig. 2C). Eleven insertions were isolated when the wild-type gene was upstream of the sup2G56 gene, and 14 insertions were recovered when the wild-type gene was present downstream. The mutation in box $B$ of the sup2G56 gene therefore decreased its ability both to assemble the poly-
B
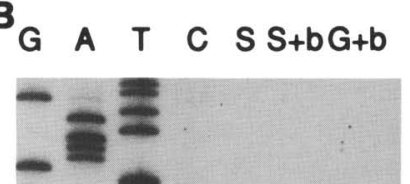

w $\underline{-}$
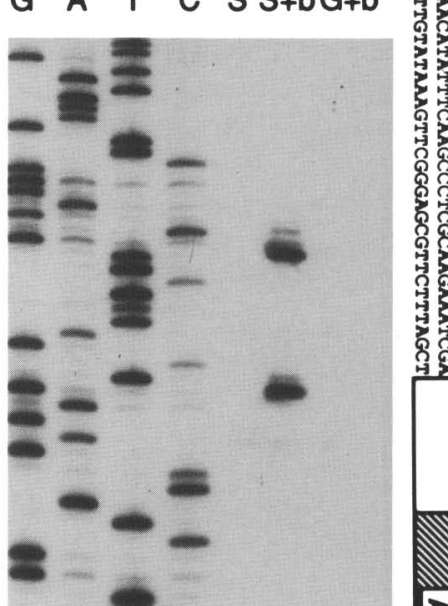

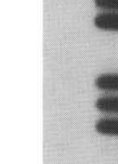

.

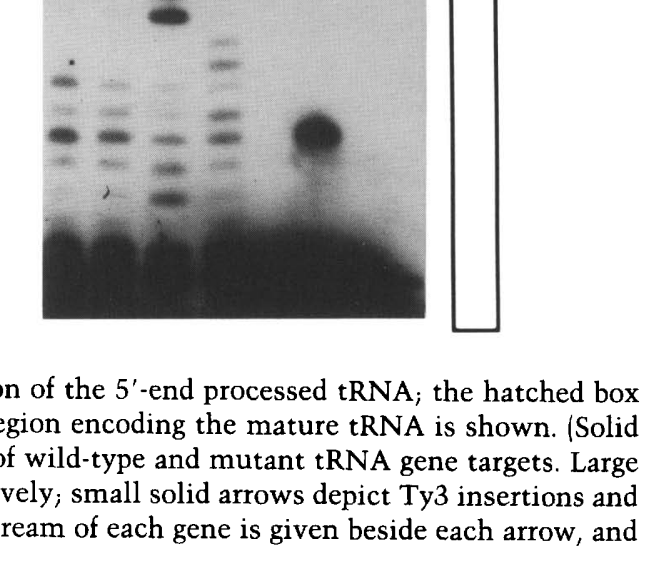

merase III transcription factors and to function as a target for Ty3 transposition. A deletion of the box $A$ promoter element and $\sim 40 \mathrm{bp}$ of neighboring sequence from the sup $2+b$ gene eliminated detectable transcripts in vivo as determined by primer extension analysis and also eliminated the ability of the gene to serve as an efficient target (discussed in more detail below). Together, these results showed that promoter elements are important for targeting Ty3 integration.

\section{Ty3 integration occurs in the region of transcription initiation of class III genes}

Because the plasmid target assay showed that polymerase III promoter elements are important to target Ty3 to tRNA genes, we investigated whether other genes transcribed by RNA polymerase III, the $5 \mathrm{~S}$ rRNA gene and the U6 snRNA gene, SNR6, are also targets for Ty3 integration. Because these genes utilize some transcription 
factors in common with tRNA genes, but have differences in sequence and placement of polymerase III promoter elements, these experiments offered the additional possibility of distinguishing a requirement for promoter sequences from a requirement for components of the transcription complex. Figure $3 \mathrm{~A}$ is a schematic diagram showing the different promoter elements for each of these classes of polymerase III-transcribed genes. The target activities of these genes relative to SUP2 were determined by placing each on a plasmid in tandem with the tRNA gene in both upstream and downstream positions. Ty3 recognized both $5 \mathrm{~S}$ and $\mathrm{U} 6$ genes as integration targets. In each case, however, the tRNA gene was the preferred target, even when downstream of the other gene. Overall, the $5 \mathrm{~S}$ gene was the target of 4 of 25 insertions, and the SNR6 gene was used in 8 of 46 insertions examined (Fig. 3B).

All 71 insertions recovered into plasmids carrying different combinations of the SUP2, 5S, and/or U6 genes were shown by restriction digestion analysis to be near the $5^{\prime}$ end of one of the polymerase III-transcribed genes. The sites of a subset of Ty3 integrations into plasmids containing these class III genes, either when the test gene was alone on a plasmid or in tandem with a SUP2 gene, were defined further by DNA sequence analysis, and the results for 14 insertions targeted to SUP2 (discussed above), 5 targeted to $5 \mathrm{~S}$, and 9 targeted to SNR6 are presented in Figure 3B. Remarkably, the beginning of Ty3 sequences upstream of each gene was concentrated within a 2- to 4-nucleotide region. In each case, the position of the insertion was within the region of transcription initiation, located so that the gene-proximal site of nicking would have been within 3 nucleotides of the polymerase III transcription initiation site. Therefore, despite differences in primary sequence and in spacing of the promoter elements, the site of Ty3 integration upstream of different class III genes was within the region of transcription initiation.

The finding that each of these class III genes acted as a Ty3 integration target and that the sites of integration were all within the region of transcription initiation suggested a role for the transcription complex or even transcription initiation in Ty 3 targeting. By modifying the SUP2 gene site of initiation, we tested whether integration was linked (1) to specific DNA sequences contained within this region, (2) exactly to the start-site nucleotide, or (3) more generally to the region within which polymerase III initiates transcription. Two altered SUP2 targets were constructed in which the context of initiation was modified (shown schematically in Fig. 4A), and the effect of the modification on transcription was monitored by reverse primer extension of RNA isolated from cells containing these mutated genes (Fig. 4B,C). RNA polymerase III preferentially intiates transcription with a
A

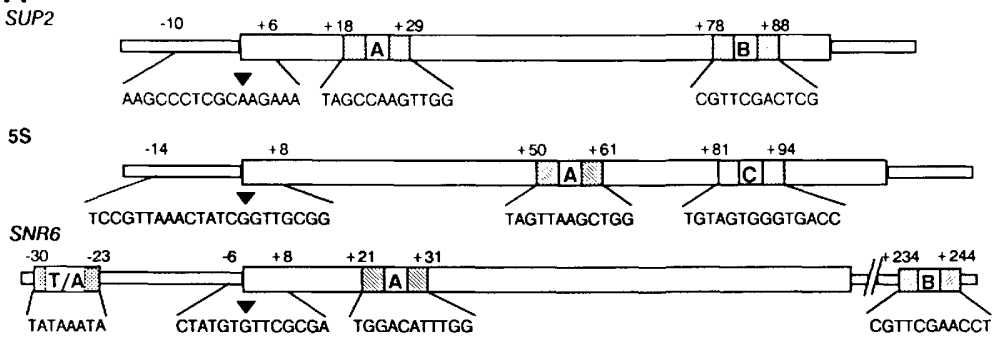

B
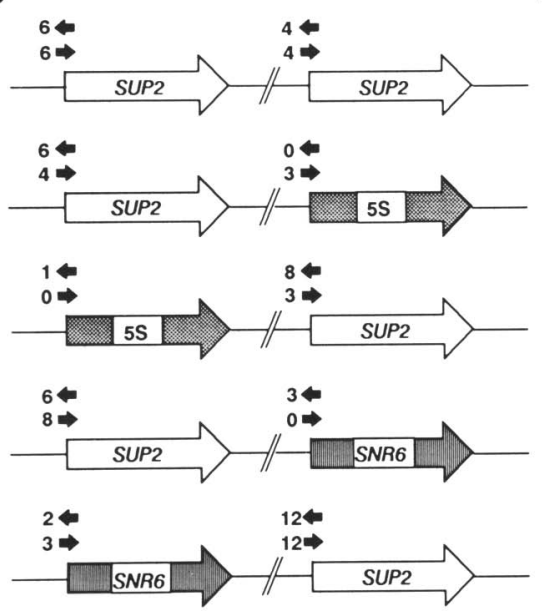

21:4

Relative target activity SUP2: test gene Ty3 insertion sites 12: $8 \quad-4 /+1$ (1) $\begin{array}{rrr}-5 / & -1 & (10) \\ -6 / & -2 & (1)\end{array}$ $-7 / \quad-3 \quad(2)$

$38: 8$
Figure 3. Ty3 integration in the region of the polymerase III transcription initiation. $(A \mid \mathrm{A}$ schematic diagram of the SUP2 tRNA ${ }^{\mathrm{Tyr}}$, 5S rRNA, and U6 snRNA (SNR6) genes is shown. Wide, open boxes represent the transcribed portion of each gene; hatched and shaded boxes depict consensus promoter elements box $A$, box $B$, box $C$, and the TATA box. The box $A$ consensus is shown for both $5 S$ and U6 genes, although it is not known to be essential for transcription of either gene. A sequence from -14 to +8 shown to be required for $5 \mathrm{~S}$ expression in yeast is also diagrammed (Challice and Segall 1989). DNA sequences of promoter elements, regions of transcription initiation, and their corresponding positions within each gene are given. The major transcription initiation sites of each gene are aligned and denoted $(\nabla) .(B) 5 S$ and U6 genes (wide, shaded arrows) were placed on the target plasmid in tandem with the SUP2 gene (wide, open arrows) in both the upstream and downstream positions. The position and orientation of insertions are indicated and summarized as described in the legend to Fig. 2. The sites of insertion are indicated as the Ty3-proximal and -distal nucleotide, respectively, of the 5-bp host sequence duplication generated upon integration. Numbering is relative to the transcription initiation nucleotide of each gene. Insertion sites on plasmids containing the test gene alone or in tandem with a $S U P 2$ gene were mapped by DNA sequence analysis. The number of integrations observed at each position is indicated in parentheses. 


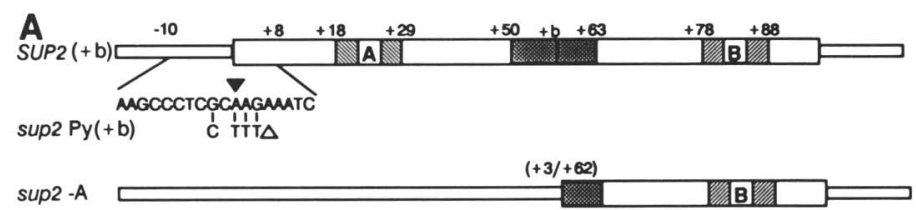

sup2 +A

D

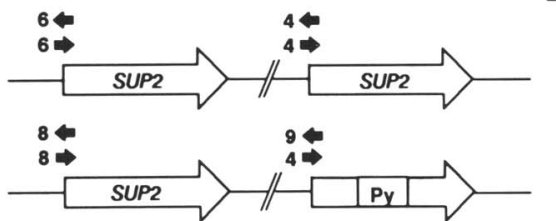

Relative target activity SUP2 : test gene

12: 8

$16: 13$

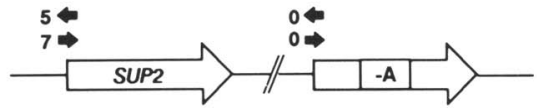

$12: 0$

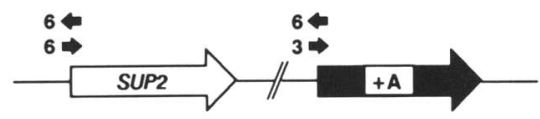

12:9
$B_{G}$

Tyz insertion sites

$\begin{array}{rr}-4 /+1 & (1) \\ -5 /-1 & (10) \\ -6 /-2 & (1) \\ -7 /-3 & (2) \\ & \\ -5 /-1 & (3) \\ -6 /-2 & (8)\end{array}$

$$
\begin{aligned}
& -3 /+2 \\
& -5 /-1 \\
& -6 /-2
\end{aligned}
$$

(3)

(6)
(2)

Figure 4. Linkage between $\mathrm{Ty} 3$ integration and the region of transcription initiation, and effects of transcriptional activity on targeting efficiency. $(A)$ A diagram of the wild-type SUP2 gene and three mutant constructs used to investigate Ty3 integration is shown. The sequence of the region of transcription initiation is given. Nucleotide positions indicated above SUP2 correspond to the wild-type gene. The sup2Py gene contains nucleotide substitutions of pyrimidines for the purine residues in the region of wild-type transcription initiation. These substitutions altered the start site from +1 (solid arrowhead) to the first available purine at +4 (open arrownhead). A larger perturbation in the transcription initiation site was created by deleting nucleotides, including the box $A$ promoter element $(\sup 2-A \mid,+3$ to +62 of sup $2 P y+b$, and introducing a new box $A$ sequence upstream of the wild-type, transcription start site $($ sup $2+A)$. The new initiation site (solid arrowhead) is at position -43 , relative to the wild-type SUP2 start site. Nucleotide positions indicated are relative to this new initiation site as +1 ; the positions relative to the wild-type SUP2 are shown in parentheses. (B) Primer extension analyses were performed to determine transcription initiation sites and levels of pre-tRNA using total RNA isolated from cells transformed with target plasmids bearing the wild-type SUP2 $(\mathrm{S})$, the sup $2+b(\mathrm{~S}+\mathrm{b})$, or the sup $2 P y+b(\mathrm{Py})$ primed with a ${ }^{32} \mathrm{P}$-labeled oligonucleotide specific to the $+\mathrm{b}$ pre-tRNA. For comparison of transcription levels, both equivalent amounts of the sup $2+b$ and the sup $2 P y+b$ extension reaction, as well as a $1: 10$ dilution of the $\sup 2+b$ extension reaction, are shown. The DNA sequence ladder was generated using sup $2+b$ DNA and the same labeled sup $2+b$ specific primer. The open box depicts the coding region of the 5 '-end processed tRNA; the hatched box indicates the boxA promoter element. The nucleotide sequence of the gene upstream of the mature $5^{\prime}$ end is shown. The nucleotides substituted for purine residues to create the sup $2 P y+b$ are shown at right. The solid arrowhead denotes the sup $2+b$ major transcription initiation site; the open arrowhead marks the sup $2 P y+b$ start site. $(C)$ Total
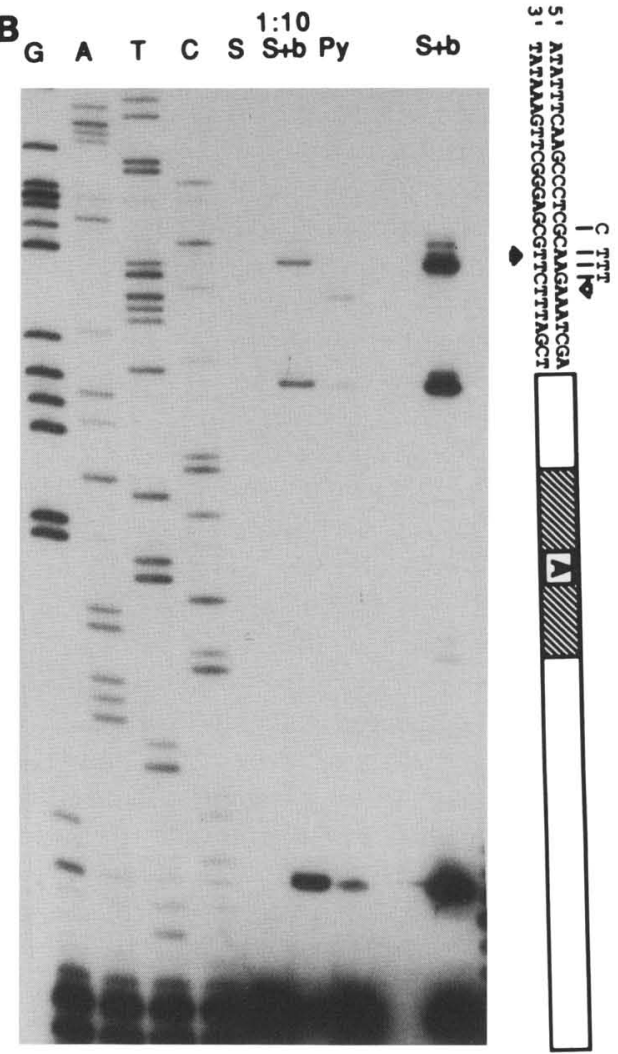

C

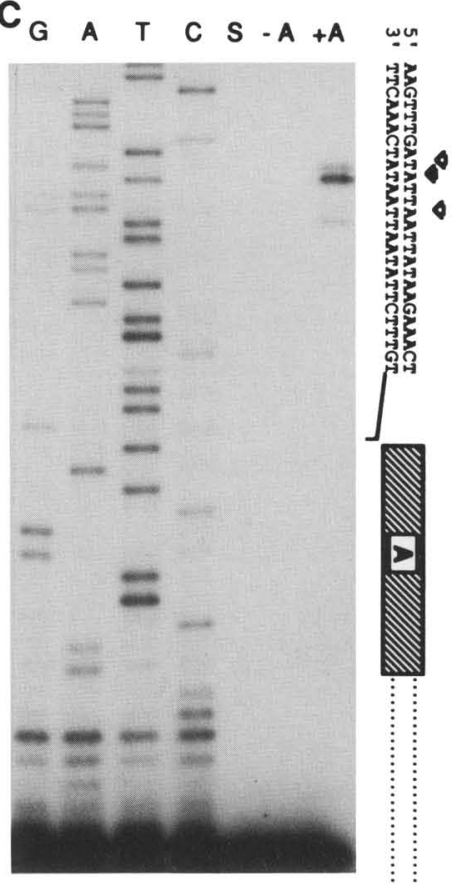
RNA isolated from cells transformed with target plasmids bearing either the wild-type SUP2 (S), the sup2 $-A(-\mathrm{A})$, or the sup2 $+A$ $(+\mathrm{A})$ was used for primer extension analysis using a ${ }^{32} \mathrm{P}$-labeled oligonucleotide spanning the deletion junction of the mutant constructs. The DNA sequence ladder was generated using sup $2+A$ DNA and the same, labeled sup $2+A$-specific primer. The hatched box indicates the boxA promoter element. The nucleotide sequence of the gene upstream of the box $A$ sequence is shown. The solid arrowhead denotes the sup $2+A$ major transcription initiation site; the open arrowheads mark alternate start or end processing sites. $(D)$ Relative target activities of $\sup 2 P y+b$, sup $2-A$, and sup $2+A$ (wide, shaded arrows) in tandem on target plasmids are compared with SUP2 (wide, open arrows). Results are summarized as described in the legend to Fig. 2 . The sites of integration upstream of SUP2 and sup $2 P y+b$ are given relative to the wild-type $S U P 2$ initiation site as +1 . The insertion sites upstream of sup $2+A$ are shown relative to the new initiation site $(+1)$ for that gene. 
purine nucleotide. In the first construct, four pyrimidine nucleotides were substituted for purine nucleotides surrounding and including the initiation nucleotide of the sup $2+b$ gene to produce sup2Py $+b$. The high-copy target plasmid carrying the sup $2+b$ or mutant tRNA gene was transformed into strain yDLC221 together with the Ty3-N donor plasmid. RNA was isolated from these transformants, and the effect of the nucleotide substitutions on transcription was analyzed by reverse primer extension using the sup $2+b$-specific oligonucleotide (Fig. 4B). Transcription of the sup2Py $+b$ gene initiated at the first available purine, position +4 relative to the wild-type start at position +1 . In addition, the sup $2 P y+b$ gene pre-tRNAs were present at less than one-tenth the level of the pre-tRNAs from the wild-type control genes (discussed below), suggesting that transcription initiation did not occur efficiently on this mutant template.

Target plasmids, containing sup $2 P y+b$ into which Ty 3 had integrated, were isolated, and the positions of 11 Ty3 integration sites upstream of $\sup 2 P y+b$ were determined by DNA sequence analysis. Ty3 insertions occurred at the same positions as observed for the wildtype gene, with the Ty3 sequence beginning 16 or 17 nucleotides $5^{\prime}$ of the coding region for the mature tRNA (Fig. 4D). The predominant insertion site $5^{\prime}$ of sup $2 P y+b$ was actually 1 nucleotide farther upstream than the predominant insertion site of the wild-type gene so that target nicking must have occurred 3-4 nucleotides upstream of the transcription start site. Therefore, the change in initiation site did not cause a similar shift of the Ty3 integration site.

To determine whether the observed association between the position of integration and the site of transcription initiation is linked with particular sequences at the insertion site or reflects a more general association with the region of initiation, a target was constructed that contained the sequences surrounding the site at which Ty3 integration occurred in the unaltered gene, but in which the site of transcription initiation was shifted to an upstream position. This test gene was constructed by deletion of the wild-type box $A$ along with $\sim 40 \mathrm{bp}$ of surrounding sequence from sup $2 P y+b$ $($ sup $2-A)$, followed by introduction of a box $A$ consensus upstream of the original transcription initiation site $(\sup 2+A)$. Each of these constructs was placed on the high-copy target plasmid and transformed into yDLC221 along with the Ty3-N donor plasmid. The transcriptional activity of each mutant construct was determined by primer extension analysis using template RNA isolated from the appropriate transformants and a primer oligonucleotide spanning the box $A$ deletion junction. This primer ensured specific detection of products expressed from the plasmid-borne templates. No transcripts were detected from the sup $2-A$ gene. Insertion of the box $A$ sequence upstream of the original start site, however, restored transcription. The major site of transcription initiation was mapped by reverse primer extension to a position 17 nucleotides upstream of box $A$, the same distance as the wild-type start site is from the nat- ural box $A$ (Fig. 4C). To simplify comparisons of the insertion sites, the sup $2+A$ initiation site lat position -43 relative to the wild-type start site) is designated +1 . Minor species were generated in the primer extension reactions that could correspond to transcripts from alternative start sites or to processed transcripts. Nevertheless, it is clear that the site at which transcription starts is in a new sequence context with the unused, original initiation-site context downstream.

The box $A$ mutant genes were cloned into a target plasmid in tandem with a wild-type SUP2 gene to determine their relative target activity. When the sup $2-A$ gene was tested, 12 of 12 Ty3 insertions were observed upstream of the wild-type gene (Fig. 4D). However, of 21 insertions into the target plasmid carrying both the sup $2+A$ and SUP2 genes examined, 9 were associated with the mutant gene. A total of 11 insertions associated with the sup $2+A$ gene, either when alone or in tandem with the SUP2 gene, were mapped by DNA sequence analysis. Of these, all occurred so that the gene-proximal nick site was within 2 nucleotides of the new transcription initiation site (Fig. 4D). Thus, despite retention of the original insertion site sequences downstream, Ty3 integrated in the functional region of transcription initiation. These data, taken together with the integration pattern at the $\sup 2 P y+b$ gene, suggested that Ty3 integrates within the region of initiation, but not at an exact site fixed by transcription initiation.

\section{Targeting efficiency is not directly related to transcriptional activity}

Mutations in the tRNA gene that eliminated detectable in vivo expression of the altered constructs, sup2G56 and sup $2-A$, also abolished Ty3 target activity of these genes. However, class III genes, which have differing promoter sequences, served as targets for Ty3 integration. These observations argued that the polymerase III transcription complex itself may target Ty3 integration. $\mathrm{Mu}$ tant tRNA genes with decreased transcription were used to assess whether integration activity of a target is simply a function of its transcriptional activity. Primer extension analysis showed that the levels of pre-tRNA expressed from the sup $2 P y+b$ gene are less than one-tenth the levels of pre-tRNA from the wild-type gene (Fig. 4B). Because only pre-tRNA is detected with this primer and because the mutant pre-tRNA is very similar in structure to the wild-type tRNA, it is most likely that the different levels of pre-tRNA observed are attributable to differences between wild-type and mutant transcription rates, rather than RNA stability. The in vivo expression of the sup $2+A$ gene could not be quantitatively compared to expression of the wild-type gene, because the oligonucleotide primer specific for sup $2+b$ pre-tRNA did not anneal to sup $2+A$ pre-tRNA. However, comparison of the levels of primer extension products synthesized from equivalent amounts of template RNA extracted from cells containing either the mutant or wildtype gene and using oligonucleotide primers of similar specific activities indicated that lower transcript levels 
were produced from the mutant gene. Transcription of sup $2 P y+b$ and sup $2+A$ templates in vitro using a partially purified RNA polymerase III transcription extract (Kassavetis et al. 1989) confirmed that the transcriptional activity of each of these genes was decreased relative to the wild-type $S U P 2$ gene, although the ratio of mutant to wild-type transcription in vitro varied somewhat from the relative levels observed in vivo (data not shown).

The sup $2 P y+b$ gene and the sup $2+A$ gene were each tested on plasmids in tandem with the wild-type gene. Independent Ty3 insertions were recovered into each plasmid and mapped. Although the transcription of each mutant gene was at least half that of the wild-type SUP2, the target use was comparable (Fig. 4D). Therefore, although the ability to form the polymerase III transcription complex is likely to be essential for Ty3 integration, the actual level of transcription of the target gene is not directly correlated with its target usage.

\section{Discussion}

We have described an assay to recover unselected retrotransposon insertions into a target plasmid. Using this assay, and the established preference of Ty 3 for transposition upstream of tRNA genes, we investigated factors that contribute to integration site selection. Ty3 transposition into the plasmid was dependent on the presence of a polymerase III-transcribed gene. A polymerase IItranscribed gene, TRP1, placed on the target plasmid and not required for plasmid maintenance, did not serve as a transposition target (data not shown). Of $178 \mathrm{Ty} 3$ insertions into plasmids carrying tandem polymerase III genes, as well as several insertions recovered into plasmids bearing a single test gene, integration occurred immediately upstream of class III genes exclusively. In 49 cases, where the position of insertion was determined by DNA sequence analysis, target-proximal nicking was within $1-4 \mathrm{bp}$ of the transcription initiation site. Ty3 transposition was dependent on the presence of intact promoter elements. Mutation of the $\operatorname{box} B$ promoter element or deletion of the boxA sequences from a SUP2 gene destroyed its ability to serve as an integration target.

Integrations upstream of the plasmid-borne SUP2 tRNA gene were into the same positions as insertions previously characterized upstream of genomic tRNA genes. Nevertheless, transposition into target plasmids differed from genomic integration in two ways. First, 5S genes were used as targets, although at one-fifth the frequency that tRNA genes were used as targets. In a survey of 91 independent genomic Ty3 insertions, no integrations were observed in association with the estimated 140 genomic 5S genes (Chalker and Sandmeyer 1990). Even taking into account the apparent reduced targeting of plasmid-based genes relative to a control SUP2 tRNA gene on the same plasmid, several insertions upstream of $5 \mathrm{~S}$ genes should have been recovered in the genomic sample. The location of $5 \mathrm{~S}$ genes in Saccharomyces cerevisiae within a large, tandem rDNA repeat contained within the nucleolus (Bell et al. 1977) could potentially limit the availability of these genes as transposition targets. A second apparent difference between genomic and plasmid Ty3 insertions is in the constancy of their orientation relative to the target gene. Analysis of seven genomic tRNA gene loci used as targets in two or three independent integrations revealed that the orientations of the integrated Ty3 elements were the same at any particular locus (Chalker and Sandmeyer 1990). In addition, two-thirds of endogenous $\sigma$-element insertions that have been characterized have been found to be oriented so that transcription from the element is divergent to transcription of the adjacent tRNA gene (Sandmeyer et al. 1988). Insertions into the plasmid-borne SUP2 gene were less biased with respect to orientation. Of a total 144 insertions upstream of the SUP2 gene examined in this study, 76 integrated so that directions of transcription of the Ty3 and the tRNA gene were divergent, and 68 integrated in the opposite orientation. Thus, our data suggest that genomic organization can constrain target site usage and that plasmid-borne targets consisting of more localized sequences are not subject to the same constraints. These differences could relate to the state of the chromatin assembled on sequences flanking the target, to functions of flanking sequences, or to nuclear localization.

Three general models are formally consistent with our findings that genes transcribed by RNA polymerase III are targets of Ty3 transposition. These are depicted in Figure 5. Model I postulates that DNA sequence (e.g., promoter elements box $A$ and/or box $B$ ) or conformation are directly responsible for targeting Ty3 integration.

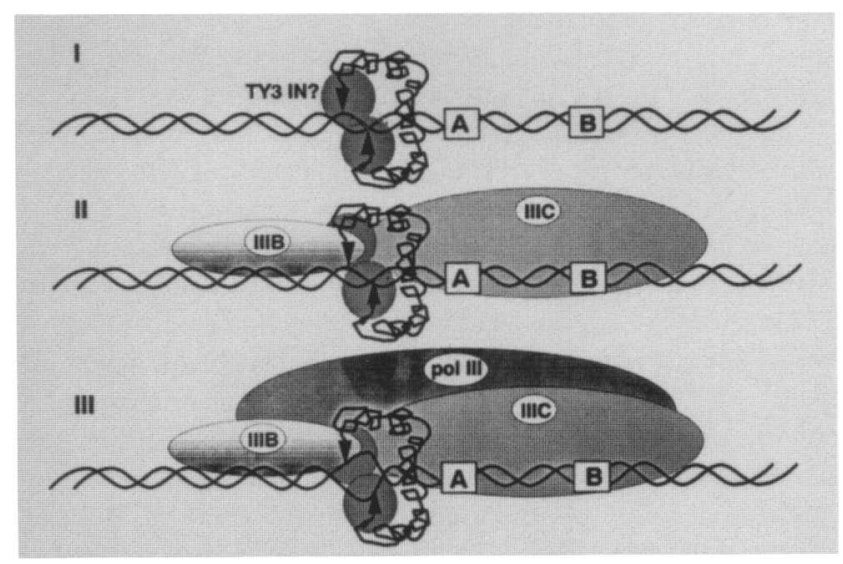

Figure 5. Models for interaction of the Ty3 integration machinery and the tRNA gene target. The hypothetical Ty3 integration complex, consisting of the linear Ty3 DNA bound at its ends by the Ty3 IN, is shown recognizing three possible tRNA gene target configurations in the region of transcription initiation. Internal promoter elements box $A$ and box $B$ are shown on the DNA to indicate the orientation of the gene. Transcription factor positions are approximate. Model I shows that the tDNA itself is sufficient to mediate this interaction; model II shows that transcription factors TFIIIB and/or TFIIIC must assemble on the gene to create the target; model III proposes that polymerase, but not necessarily transcription, is required for presentation of the target to the integration machinery. 
This model seems the least plausible because of the diversity of primary sequences and promoter element spacing represented by the three different classes of target genes. Transcription of these different genes requires recognition of the template by multiple protein factors, and notably, none of them act independently of other proteins on all three genes. In addition, because two to four different sites were targeted upstream of the genes studied, a flexibility is implied that seems incompatible with targeting by a specific DNA sequence or structure. Behavior of mutated targets was also not consistent with DNA targeting. Gross changes in the context of transcription initiation did not disrupt its regional association with integration; whereas a single nucleotide change distal to the target site, which eliminates transcription factor assembly, altered target activity dramatically.

According to the second model, transcription factors assemble on the gene to create the target. The Ty3 integration machinery could interact directly with proteins of the transcription complex or could recognize an altered DNA conformation induced by transcription factor binding. DNA bending is important for bacteriophage $\lambda$ (Goodman and Nash 1989; Snyder et al. 1989) and the Saccharomyces FLP (Schwartz and Sadowski 1989) recombination reactions. Both transcription factors TFIIIC and TFIIIB induce a bend centered near the transcription initiation site when bound to a tRNA ${ }^{\text {Gln }}$ gene (Leveillard et al. 1991). An altered conformation could increase the availability of protein and/or DNA for interaction with the Ty3 integration apparatus.

It is useful to consider which transcription factors are likely candidates for mediating interactions of the Ty3 integration complex with its target. Despite the differences in promoter elements among the three classes of polymerase III genes, the requirement for at least some common factor(s) is striking. TFIIIB is known to be essential for transcription of each class of polymerase IIItranscribed gene (Segall et al. 1980; Shastry et al. 1982; Moenne et al. 1990). In vitro footprint analysis using DNase I showed that TFIIIB alone protected the SUP4 tRNA $^{\text {Tyx }}$ gene $5^{\prime}$ flank beginning at position -4 on the nontranscribed strand (relative to the initiation site) and protected the $5 \mathrm{~S}$ gene $5^{\prime}$ flank beginning at position -8 and extending $\sim 45$ nucleotides upstream in both cases (Braun et al. 1989; Kassavetis et al. 1989, 1990). In addition, TFIIIB-bound templates show enhanced DNase I cleavage at or near the start site of each gene. The position of TFIIIB upstream of the gene and its ability to direct polymerase III initiation make this factor an intriguing candidate for recognition by the Ty3 transposition complex. The Dictyostelium repeated element (DRE) is also found integrated exclusively upstream of tRNA genes, but at position $-50( \pm 3$ nucleotides $)$ (Marschalek et al. 1989). If TFIIIB binds similarly in yeast and Dictyostelium, DRE integration would occur at the upstream boundary of the TFIIIB/DNA interaction.

TFIIIC is essential for both tRNA and 5S expression (for review, see Geiduschek and Tocchini-Valentini 1988) and is likely to have a role in U6 transcription in yeast as well (Brow and Guthrie 1990). This factor directs TFIIIB binding to the $5^{\prime}$ flank of these class III genes (Braun et al. 1989; Kassavetis et al. 1989). TFIIIC, alone or in combination with other transcription factors, could direct the Ty3 integration machinery to the transcription initiation region of the target gene in a manner similar to the way in which it interacts with TFIIIB. The gene-specific factors assembled with TFIIIC in the transcription complex, for instance, TFIIIA for $5 \mathrm{~S}$ (Engelke et al. 1980) and TFIID for U6 (Margottin et al. 1991), could account for the observed differences in target efficiency observed between these different class III genes.

Model III proposes that polymerase itself is required for Ty3 targeting. Active transcription is not necessarily required by this model. The Ty3 integration machinery could recognize a polymerase III subunit or a polymerase III-dependent DNA conformation. Kassavetis et al. (1990) have identified a region of single-stranded DNA extending from at least -7 to +7 by permanganate probing of polymerase associated with the transcription complex. Hence, the interaction of polymerase III with the DNA near the initiation site is within the region that is targeted by Ty3 during integration. The distribution of insertion sites $5^{\prime}$ of the sup2Py gene, relative to those at SUP2, may indicate that polymerase III is present upon integration. The sup $2 P y+b$ transcription initiation site shifted downstream 3 nucleotides, yet contains no changes in the promoter elements that direct factor binding. The predominant insertion site $5^{\prime}$ of this mutant gene, however, was 1 nucleotide upstream of the predominant SUP2 insertion site. An altered conformation of the transcription complex or a repositioning of polymerase may make the upstream site more accessible to Ty3 for integration. Alternatively, the sequence of the mutant gene in the region of integration simply may favor use of the upstream insertion site. Whether actual transcription of the target gene by polymerase III is required for targeting was not addressed directly by our experiments. Indirect evidence, however, suggests that target activity is not a simple function of transcriptional activity. The sup $2+A$ gene and the $\sup 2 P y+b$ gene, both of which appear to have reduced expression in vivo and in vitro, were virtually equivalent to the wild-type SUP2 gene in targeting.

The target specificity of Ty3 has facilitated identification of parameters affecting the choice of retrotransposon integration sites. Although many investigations of retroviral and retrotransposon integration have identified preferred integration sites, this is the first case correlating a preference with a specific cellular function. An obvious candidate for recognition of the class III gene target is the Ty3 IN. This protein is required for Ty3 transposition (Hansen and Sandmeyer 1990) and is homologous to retroviral IN proteins (Hansen et al. 1988), which have been shown to be sufficient for integration in vitro (Katzman et al. 1989; Craigie et al. 1990; Katz et al. 1990). Further characterization of Ty3 integration should shed light on mechanisms of target selection and possibly lead to the identification of specific interactions between host and retrotransposon proteins. 


\section{Materials and methods}

Strains

Culturing and transformation of $E$. coli and $S$. cerevisiae strains were done according to standard methodology (Ausubel et al. 1989). Transposition studies were performed using yeast strain yDLC221 (MATa ura3-52 his3-4200 ade2-101 lys2-1 leu1-12 can1-100 gal3), which contains a single, galactose-inducible Ty3 element introduced by integrative transformation /Chalker and Sandmeyer 1990|. Galactose induction of the integrated Ty3 complemented transposition of a defective Ty3 element tagged with a selectable marker.

Single-stranded DNA used for site-directed oligonucleotide mutagenesis was generated in E. coli strain RZ1032 [1ysA (6162) thi-1 relA1 spoT1 dut-1 ung-1 (tet ${ }^{r}$ ) supE44] as described by International Biotechnologies, Inc. Other plasmid manipulations were performed using $E$. coli strain HB101 $\left[F^{-}\right.$hsdS2O $\left({ }^{r} B^{-},{ }^{m} B^{-}\right)$recA13 leuB6 ara-14 proA2 lacY1 galK2 $\mathrm{rps} L 20\left(\mathrm{sm}^{\mathrm{r}}\right)$

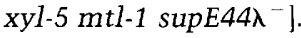

\section{Plasmid constructions}

All recombinant DNA techniques were performed essentially as described in Ausubel et al. (1989). Plasmid pDLC348, which served as the Ty 3 donor in the transposition studies described, was constructed as follows: The galactose-inducible Ty3 element derived from plasmid pEGTy3-1 (Hansen et al. 1988) was tagged by inserting a 1060-bp BamHI fragment bearing the bacterial neo ${ }^{\mathrm{x}}$ gene from pGH54 (Joyce and Grindley 1984) into a BamHI site, starting at nucleotide position 4882 of the Ty3-1 sequence, introduced by site-directed oligonucleotide mutagenesis (Chalker and Sandmeyer 1990). An EcoRI-HindIII fragment containing both the marked Ty3-N element and the yeast $U R A 3$ gene was ligated to the EcoRI-HindIII vector fragment of piAN7 (Seed 1983). The resulting plasmid was made into a lowcopy yeast vector by inserting a $2.7-\mathrm{kbp}$ EcoRI fragment containing ARS1 and CEN4 into the EcoRI site downstream of the Ty3 element.

A high-copy target vector, pDLC237, was constructed by inserting an 880 -bp BamHI-PstI fragment containing the yeast HIS3 gene derived from pDG201 la gift from D. Garfinkel, Frederick Cancer Research and Development Center, Frederick, $\mathrm{MD}$ ) and a 2.2-kbp EcoRI fragment bearing the yeast 2- $\mu \mathrm{m}$ episome from YEp24 into the BamHI-PstI and EcoRI sites, respectively, of pIBI20 (International Biotechnologies, Inc). Fragments bearing yeast genes tested for target activity were inserted between the EcoRI and SmaI sites of pDLC237 that lie between the $2-\mu \mathrm{m}$ and HIS3 sequences. Modified SUP2 genes containing $6 \mathrm{bp}$, creating a BstEII site, inserted by site-directed mutagenesis into the 14-bp intron, are denoted by $+b$. The fragments with plasmid names given in parentheses were as follows: SUP2 (pDLC300), sup2 $+b$ (pDLC356), and sup2G56 $+b$ (pDLC565), each contained on a $1-\mathrm{kbp}$ EcoRI-PvuII fragment from pPM57 (Sandmeyer and Olson 1982) or mutated derivatives (Kinsey and Sandmeyer 1991); sup2G56 (pDLC315), on a 1-kbp EcoRIEcoRV fragment; 5S (pDLC301), on a 342-bp EcoRI-PvuII fragment from pBB111R (Braun et al. 1989); and SNR6 (pDLC369), on an 1163-bp EcoRI-HincII fragment from p589-H6 (Brow and Guthrie 1990).

To construct target plasmids carrying test genes in a tandem array, the fragments mentioned above were inserted between EcoRI and SmaI sites of pDLC340, a pIBI20-piAN7 chimera containing two adjacent polylinkers created by ligating together the two vectors cut with HindIII. The plasmids that resulted from inserting the test gene fragments into pDLC340 contain each gene flanked by EcoRI sites. These EcoRI fragments were cloned into the $E c o R I$ site present between the 2 - $\mu \mathrm{m}$ sequences and the residing test gene of the target plasmids so that the direction of transcription of each test gene was the same.

The DNA sequences between nucleotide positions +3 and +62 encompassing the SUP2 boxA promoter element were deleted from plasmid pDLC363 that carried the sup2Py $+b$ gene to create the sup2 $-A$ gene. The DNA was partially digested with DraI and digested to completion with BstEII, the ends were filled in using the Klenow fragment of DNA polymerase, and the DNA was circularized. Recovery of the mutant plasmid, pDLC373, was confirmed by DNA sequence analysis.

Site-directed oligonucleotide mutagenesis was performed by the method of Kunkel (1985). The sup $2 P y+b$ gene containing pyrimidines substituted for purines in the region of transcription initiation of the wild-type SUP2 gene (see Fig. 4) was created by mutagenesis of pDLC356 using the oligonucleotide $5^{\prime}$ TTCAAGCCCTCCCTTTAAATCGACTCTCGG-3'. A box $A$ promoter element was introduced into pDLC373 bearing the sup $2-A$ construct using the oligonucleotide 5'-AAGAAACATAGCCAAGTTGGTTTCAAGCCC-3', resulting in a 10-nucleotide insertion between positions -14 and -15 upstream of the SUP2 initiation site.

\section{Recovery of target plasmids containing Ty3 insertions}

yDLC221 cells were cotransformed with the Ty3-N donor plasmid pDLC348 and a target plasmid bearing the test gene of interest. Transposition was induced in isolated colonies by growing cells at $30^{\circ} \mathrm{C}$ on synthetic galactose-containing medium lacking both uracil and histidine, thus requiring retention of both plasmids. After 4 to 6 days, single colonies were transferred as patches of cells to rich medium (YPD containing $1 \%$ yeast extract, $2 \%$ Bacto-peptone, and $2 \%$ glucose) containing $0.7 \mathrm{~g} /$ liter of G418 and grown at $30^{\circ} \mathrm{C}$ for $36-48 \mathrm{hr}$. Patches were then replica plated to synthetic medium containing both 5-FOA (Boeke et al. 1984) and G418 at $\mathrm{l}$ and $0.7 \mathrm{~g} /$ liter, respectively, to select for G418-resistant cells that had lost the URA3 donor plasmid. Colonies from these plates were transferred to synthetic medium lacking histidine to screen for cosegregation of the target plasmid with the G418-resistance phenotype. DNA was isolated from his ${ }^{+}$cells and used to transform E. coli to both ampicillin and kanamycin resistance. Plasmid DNA was extracted from $E$. coli transformants, each representing a single, galactose-induced colony, and analyzed for Ty3 integrants by restriction digestion. The positions of Ty3 insertions were determined by DNA sequence analysis using the method of Sanger et al. (1977) and the Sequenase enzyme (U.S. Biochemical).

In experiments comparing target activity, two genes in tandem on a high-copy plasmid were cotransformed with donor plasmid pDLC348 and assayed as described above. Target plasmids recovered in $E$. coli and conferring double antibiotic resistance were digested with EcoRI to identify the gene at which integration occurred and digested with BamHI to determine the orientation of insertion.

\section{Primer extension analysis of $t R N A$ species}

Expression of tRNA gene targets was evaluated by primer extension. Yeast cells transformed with high-copy plasmids bearing the various test target genes were grown in synthetic medium lacking histidine and containing glucose to an $\mathrm{OD}_{600}$ between 0.5 and 0.8. Cells were harvested, and total RNA was extracted as described previously (Clark et al. 1988). Oligonucleotide primers bound to the template RNAs $(20 \mu \mathrm{g}$ per reaction) were extended using purified reverse transcriptase (Life 
Sciences, Inc.) by the method of Carey et al. (1986). These oligonucleotides were specific to the plasmid-based gene and radiolabeled with ${ }^{32} \mathrm{P}$. For $+b$ genes described above, this specificity was mediated by a 6-bp sequence inserted into the 14-bp intron of $S U P 2$, generating a BstEII restriction site. Pre-tRNAs containing this insertion were detected by primer extension using a sup $2+b$-specific oligonucleotide (Kinsey and Sandmeyer 1991). An oligonucleotide (5'-CGTAGGTTACAAAGGGAGGGCT-3') spanning the deletion junction in the sup2-A and sup $2+A$ genes was used for the analysis of RNAs produced from these constructs. DNA sequence ladders were synthesized by annealing these specific, end-labeled oligonucleotides to plasmid DNA and extending in the presence of dideoxynucleotides and Sequenase (U.S. Biochemical). Primer extension products were visualized by electrophoresis in $8 \%$ polyacrylamide/bis $(20: 1) / 7 \mathrm{M}$ urea gels followed by autoradiography.

\section{Acknowledgments}

We thank Philip Kinsey for providing clones and the polymerase III transcription extract as well as for helpful discussions. Charles Connolly was also instrumental in purification of the transcription extract. We also thank Long Hoang for excellent technical assistance early in the development of the plasmid target assay, David Brow for the gift of the SNR6 gene, Daniel Riggs and E. Peter Geiduschek for providing the $5 \mathrm{~S}$ clone, and Peter Pryciak and Harold Varmus for communicating results prior to publication. This work was supported by U.S. Public Health Service grant GM 33281 to S.B.S. from the National Institutes of Health. D.L.C. was supported by a predoctoral training grant (GM 07134) and the University of California Systemwide Biotechnology Research and Education Program Fellowship (13913).

The publication costs of this article were defrayed in part by payment of page charges. This article must therefore be hereby marked "advertisement" in accordance with 18 USC section 1734 solely to indicate this fact.

\section{References}

Allison, D.S., S.H. Goh, and B.D. Hall. 1983. The promoter sequence of a yeast tRNA ${ }^{\mathrm{Tyr}}$ gene. Cell 34: 655-664.

Ausubel, F.M., R. Brent, R.E. Kingston, D.D. Moore, J.G. Seidman, J.A. Smith, and K. Struhl. 1989. Current protocols in molecular biology. Greene Publishing Associates/Wiley-Interscience, New York.

Baker, R.E., O. Gabrielsen, and B.D. Hall. 1986. Effects of tRNA $^{\text {Tyr }}$ point mutations on the binding of yeast RNA polymerase III transcription factor C. J. Biol. Chem. 261: 52755282.

Bell, G.I., L.J. DeGennaro, D.H. Gelfand, R.J. Bishop, P. Valenzuela, and W.J. Rutter. 1977. Ribosomal RNA genes of Saccharomyces cerevisiae. J. Biol. Chem. 252: 8118-8125.

Boeke, J.D. and S.B. Sandmeyer. 1991. Yeast transposable elements. In The molecular and cellular biology of the yeast Saccharomyces: Genome dynamics, protein synthesis, and energetics (ed. J. Pringle, E. Jones, and J. Broach), vol. 1, pp. 193-261. Cold Spring Harbor Laboratory Press, Cold Spring Harbor, New York.

Boeke, J.D., F. LaCroute, and G.R. Fink. 1984. A positive selection for mutants lacking orotidine-5'-phosphate decarboxylase activity in yeast: 5-Fluoro-orotic acid resistance. Mol. Gen. Genet. 197: 345-346.

Bowerman, B., P.O. Brown, J.M. Bishop, and H.E. Varmus. 1989. A nucleoprotein complex mediates the integration of retro- viral DNA. Genes \& Dev. 3: 469-478.

Braun, B.R., D.L. Riggs, G.A. Kassavetis, and E.P. Geiduschek. 1989. Multiple states of protein-DNA interaction in the assembly of transcription complexes on Saccharomyces cerevisiae 5S ribosomal RNA genes. Proc. Natl. Acad. Sci. 86: $2530-2534$.

Brow, D.A. and C. Guthrie. 1990. Transcription of a yeast U6 snRNA gene requires a polymerase III promoter element in a novel position. Genes \& Dev. 4: 1345-1356.

Brown, P.O., B. Bowerman, H.E. Varmus, and J.M. Bishop. 1987. Correct integration of retroviral DNA in vitro. Cell 49: $347-$ 356.

Camier, S., O. Gabrielsen, R. Baker, and A. Sentenac. 1985. A split binding site for transcription factor tau on the tRNA $_{3}{ }^{\text {Glu }}$ gene. EMBO /. 4: 491-500.

Carey, M.F., K. Singh, M. Botchan, and N.R. Cozzarelli. 1986. Induction of specific transcription by RNA polymerase III in transformed cells. Mol. Cell Biol. 6: 3068-3076.

Chalker, D.L. and S.B. Sandmeyer. 1990. Transfer RNA genes are genomic targets for de novo transposition of the yeast retrotransposon Ty3. Genetics 126: 837-850.

Challice, J.M. and J. Segall. 1989. Transcription of the 5S rRNA gene of Saccharomyces cerevisiae requires a promoter element at +1 and a 14-base pair internal control region. J. Biol. Chem. 264: 20060-20067.

Ciliberto, G., G. Raugei, F. Costanzo, L. Dente, and R. Cortese. 1983. Common and interchangeable elements in the promoters of genes transcribed by RNA polymerase III. Cell 32: 725-733.

Clark, D.J., V.W. Bilanchone, L.J. Haywood, S.L. Dildine, and S.B. Sandmeyer. 1988. A yeast sigma composite element, Ty3, has properties of a retrotransposon. I. Biol. Chem. 263: $1413-1423$.

Craigie, R., T. Fujiwara, and F. Bushman. 1990. The IN protein of Moloney murine leukemia virus processes the viral DNA ends and accomplishes their integration in vitro. Cell 62: $829-837$.

Eibel, H. and P. Philippsen. 1984. Preferential integration of yeast transposable element $\mathrm{Ty}$ into a promoter region. $\mathrm{Na}$ ture 307: 386-388.

Eichinger, D.J. and J.D. Boeke. 1988. The DNA intermediate in yeast Tyl element transposition copurifies with virus-like particles: Cell-free Tyl transposition. Cell 54: 955-966.

Engelke, D.R., S.Y. Ng, B.S. Shastry, and R.G. Roeder. 1980. Specific interaction of a purified transcription factor with an internal control region of 5S RNA genes. Cell 19: 717-728.

Fujiwara, T. and R. Craigie. 1989. Integration of mini-retroviral DNA: A cell-free reaction for biochemical analysis of retroviral integration. Proc. Nat1. Acad. Sci. 86: 3065-3069.

Geiduschek, E.P. and G.P. Tocchini-Valentini. 1988. Transcription by RNA polymerase III. Annu. Rev. Biochem. 57: 873914.

Goodman, S.D. and H.A. Nash. 1989. Functional replacement of a protein-induced bend in a DNA recombination site. $\mathrm{Na}$ ture 341: 251-254.

Hansen, L.J. and S.B. Sandmeyer. 1990. Characterization of a transpositionally active Ty3 element and identification of the Ty3 IN protein. J. Virol. 64: 2599-2607.

Hansen, L.J., D.L. Chalker, and S.B. Sandmeyer. 1988. Ty3, a yeast retrotransposon associated with tRNA genes, has homology to animal retroviruses. Mol. Cell Biol. 8: 5245-5256.

Hansen, L.J., D.L. Chalker, K.J. Orlinsky, and S.B. Sandmeyer. 1991. Ty3 GAG3 and POL3 genes encode the components of intracellular particles. J. Virol. (in press).

Johnston, M. and R.W. Davis. 1984. Sequences that regulate the divergent GAL1-GAL10 promoter in Saccharomyces cerevi- 
siae. Mol. Cell Biol. 4: 1440-1448.

Joyce, C.M. and N.D.F. Grindley. 1984. Method of determining whether a gene of Escherichia coli is essential: Application to the polA gene. J. Bact. 158: 636-643.

Kassavetis, G.A., D.L. Riggs, R. Negri, L.H. Nguyen, and E.P. Geiduschek. 1989. Transcription factor IIIB generates extended DNA interactions in RNA polymerase III transcription complexes on tRNA genes. Mol. Cell Biol. 9: 25512566.

Kassavetis, G.A., B.R. Braun, L.H. Nguyen, and E.P. Geiduschek. 1990. S. cerevisiae TFIIIB is the transcription initiation factor proper of RNA polymerase III, while TFIIIA and TFIIIC are assembly factors. Cell 60: 235-245.

Katz, R.A., G. Merkel, J. Kulkosky, J. Leis, and A.M. Skalka. 1990. The avian retroviral IN protein is both necessary and sufficient for integrative recombination in vitro. Cell 63: 87-95.

Katzman, M., R.A. Katz, A.M. Skalka, and J. Leis. 1989. The avian retroviral integration protein cleaves the terminal sequences of linear viral DNA at the in vivo sites of integration. J. Virol. 63: 5319-5327.

Kinsey, P.T. and S.B. Sandmeyer. 1991. Adjacent pol II and pol III promoters: Transcription of the yeast retrotransposon Ty3 and a target tRNA gene. Nucleic Acids Res. 19: 13171324.

Kunkel, T.A. 1985. Rapid and efficient site-specific mutagenesis without phenotypic selection. Proc. Natl. Acad. Sci. 82: 488-492.

Kurjan, J. and B.D. Hall. 1982. Mutations at the Saccharomyces cerevisiae SUP4 tRNA ${ }^{\mathrm{Tyr}}$ locus: Isolation, genetic finestructure mapping, and correlation with physical structure. Mol. Cell Biol. 2: 1501-1513.

Lassar, A.B., P.L. Martin, and R.G. Roeder. 1983. Transcription of class III genes: Formation of preinitiation complexes. Science 222: 740-748.

Leveillard, T., G.A. Kassavetis, and E.P. Geiduschek. 1991. Saccharomyces cerevisiae transcription factors IIIB and IIIC bend DNA of the tRNA ${ }^{\text {Gin }}$ gene. J. Biol. Chem. 266: 51625168.

Margottin, F., G. Dujardin, M. Gerard, J.M. Egly, J. Huet, and A. Sentenac. 1991. Participation of the TATA factor in transcription of the yeast U6 gene by RNA polymerase C. Science 251: 424-426.

Marschalek, R., T. Brechner, E. Amon-Bohm, and T. Dingermann. 1989. Transfer RNA genes: Landmarks for integration of mobile genetic elements in Dictyostelium discoideum. Science 244: 1493-1496.

Moenne, A., S. Camier, G. Anderson, F. Margottin, J. Beggs, and A. Sentenac. 1990. The U6 gene of Saccharomyces cerevisiae is transcribed by RNA polymerase C (III) in vivo and in vitro. EMBO I. 9: 271-277.

Natsoulis, G., W. Thomas, M.-C. Roghmann, F. Winston, and J.D. Boeke. 1989. Tyl transposition in Saccharomyces cerevisiae is nonrandom. Genetics 123: 269-279.

Pryciak, P.M., A. Sil, and H.A. Varmus. 1991. Retroviral integration into minichromosomes in vitro. $E M B O J$. (in press).

Robinson, H.L. and G.C. Gagnon. 1986. Patterns of proviral insertion and deletion in avian leukosis virus-induced lymphomas. I. Virol. 57: 28-36.

Rohdewohld, H., H. Weiher, W. Reik, R. Jaenisch, and M. Breindl. 1987. Retrovirus integration and chromatin structure: Moloney murine leukemia proviral integration sites map near DNase I-hypersensitive sites. J. Virol. 61: 336-343.

Sandmeyer, S.B. and M.V. Olson. 1982. Insertion of a repetitive element at the same position in the 5 '-flanking regions of two dissimilar yeast tRNA genes. Proc. Natl. Acad. Sci.
79: 7674-7678.

Sandmeyer, S.B., V.W. Bilanchone, D.J. Clark, P. Morcos, G.F. Carle, and G.M. Brodeur. 1988. Sigma elements are positionspecific for many different yeast tRNA genes. Nucleic Acids Res. 16: 1499-1515.

Sandmeyer, S.B., L.J. Hansen, and D.L. Chalker 1990. Integration specificity of retrotransposons and retroviruses. Annu. Rev. Genet. 24: 491-518.

Sanger, F., S. Nicklen, and A.R. Coulson. 1977. DNA sequencing with chain-terminating inhibitors. Proc. Natl. Acad. Sci. 74: 5463-5467.

Scherdin, U., K. Rhodes, and M. Breindl. 1990. Transcriptionally active genome regions are preferred targets for retrovirus integration. J. Virol. 64: 907-912.

Schwartz, C.J. and P.D. Sadowski. 1989. FLP recombinase of the 2 micron circle plasmid of Saccharomyces cerevisiae bends its DNA target. Isolation of FLP mutants defective in DNA bending. J. Mol. Biol. 205: 647-658.

Seed, B. 1983. Purification of genomic sequences from bacteriophage libraries by recombination and selection in vivo. $\mathrm{Nu}$ cleic Acids Res. 11: 2427-2445.

Segall, J. 1986. Assembly of a yeast 5S RNA gene transcription complex. J. Biol. Chem. 261: 11578-11584.

Segall, J., T. Matsui, and R.G. Roeder. 1980. Multiple factors are required for the accurate transcription of purified genes by RNA polymerase III. J. Biol. Chem. 255: 11986-11991.

Shastry, B.S., S.Y. Ng, and R.G. Roeder. 1982. Multiple factors involved in the transcription of class III genes in Xenopus laevis. J. Biol. Chem. 257: 12979-12986.

Shih, C.C., J.P. Stoye, and J.M. Coffin. 1988. Highly preferred targets for retrovirus integration. Cell 53: 531-537.

Simchen, G., F. Winston, C.A. Styles, and G.R. Fink. 1984. Tymediated gene expression of the LYS2 and HIS4 genes of Saccharomyces cerevisiae is controlled by the same SPT genes. Proc. Natl. Acad. Sci. 81: 2431-2434.

Snyder, U.K., J.F. Thompson, and A. Landy. 1989. Phasing of protein-induced DNA bends in a recombination complex. Nature 341: 255-257.

Sprinzl, M., T. Hartmann, J. Weber, J. Blank, and R. Zeidler. 1989. Compilation of tRNA sequences and sequences of tRNA genes. Nucleic Acids Res. 17S: rl-rl74.

Vijaya, S., D.L. Steffen, and H.L. Robinson. 1986. Acceptor sites for retroviral integrations map near DNase I-hypersensitive sites in chromatin. J. Virol. 60: 683-692.

Wilke, C.M., S.H. Heidler, N. Brown, and S.W. Liebman. 1989. Analysis of yeast retrotransposon Ty insertions at the CAN1 locus. Genetics 123: 655-665. 


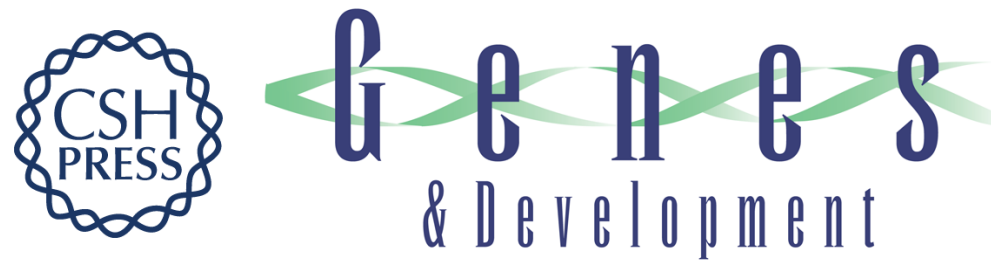

\section{Ty3 integrates within the region of RNA polymerase III transcription initiation.}

D L Chalker and S B Sandmeyer

Genes Dev. 1992, 6:

Access the most recent version at doi:10.1101/gad.6.1.117

References This article cites 56 articles, 34 of which can be accessed free at:

http://genesdev.cshlp.org/content/6/1/117.full.html\#ref-list-1

License

Email Alerting Receive free email alerts when new articles cite this article - sign up in the box at the top Service right corner of the article or click here.

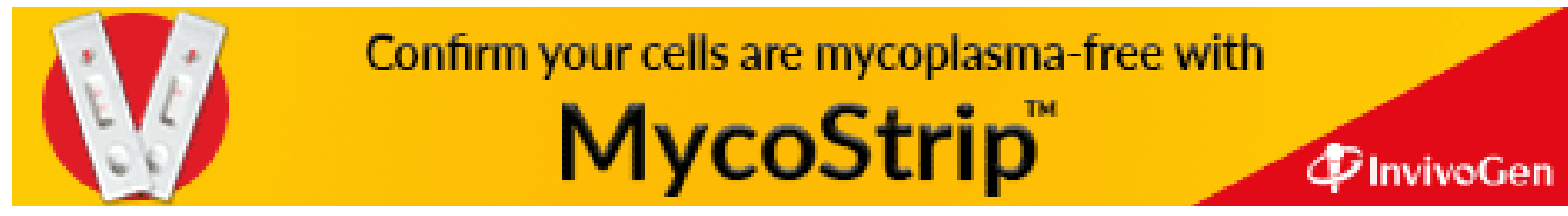

